\title{
Mapping of Landscape Cover Using Remote Sensing and GIS in Chandoli National Park, India
}

\section{Ekwal Imam}

Department of Biology, College of Natural and Computational Sciences, P.O. Box 3044, Mekelle University, Mekelle, Tigray, Ethiopia (ekwalimam01@gmail.com).

\begin{abstract}
Humankind to fulfill its needs has put natural resources of the earth to a severe pressure. The rate of degradation and depletion of earth resources has accelerated tremendously in view of the overincreasing demographic pressure. Therefore, mapping of landscape cover types to evaluate it has been a great concern for forest and wildlife managers. Both managers find it very important to know how much area is suitable for wildlife species and what areas are affected due to anthropogenic pressure. To address these concerns in Chandoli National Park its land-use landcover and forest crown density were mapped. The National Park is situated in Western Ghats, India lying within $17^{0} 04^{\prime} 00^{\prime \prime} \mathrm{N}$ to $17^{\circ} 19^{\prime} 54^{\prime \prime} \mathrm{N}$ and $73^{\circ} 40^{\prime} 43^{\prime \prime} \mathrm{E}$ to $73^{0} 53^{\prime} 09^{\prime \prime} \mathrm{E}$. In the present study, Remote Sensing (RS) and Geographical Information System (GIS) techniques were used. Remotely sensed data procured from satellite IRS-P6, LISS-III (2005) and collateral data generated from topographic maps were processed using ERDAS IMAGINE and ArcView softwares. Land-use land-cover map of the study area was prepared from satellite data using supervised maximum likelihood classification technique, which revealed that Park supports diversified landscape of scrubland $(27.37 \%)$, grassland $(20.05 \%)$, rejuvenated forest $(22.40 \%)$ and evergreen forest (16.01\%). On the other hand Normalized Difference Vegetation Index (NDVI) was used to prepare a forest crown density map, which revealed that majority of the forest cover $\left(126.10 \mathrm{~km}^{2}\right)$ was under the crown density of $40-100 \%$.
\end{abstract}

Key Words: Remote Sensing, GIS, Landscape, Chandoli National Park, Western Ghats, India.

\section{INTRODUCTION}

Over the past 200-300 years humans have been dominant drivers of landscape transformations (Vitousek et al., 1997) and have changed these landscapes to meet the growing demand for food, fodder, timber, fiber, and fuel more rapidly and extensively during last 50 years than in any comparable period of time (Millennium Ecosystem Assessment, 2005).

The drivers of landscape change operate at multiple levels that are influenced by regional, national and global institutions. Recent studies show that environmental, socio-economic, political and technological factors play a great role in landscape change (Burgi et al., 2005; Tahir \& Hussain, 2008). To fully understand the physical and human processes at work, it is important that landscape cover be mapped to evaluated and quantified accurately; as such data are of interest to resource management and planning agencies because of their value in assessing current land use patterns and in modeling future developments (Lambin et al.,1999). 
For forest managers, it is of utmost importance to know the precise status of their resources spatially, the location and extent of various vegetation classes within them, the impact and progress of various actions undertaken, and extent of the change along with their trends and patterns. Information about the change is also necessary for updating land cover maps and the management of natural resources.

The tropical region in general is witnessing an accelerated rate of degradation as documented by U.N. (FAO, 1990). The average annual deforestation during the past decade amounts to 15.4 million hectares per year with a compound annual rate of deforestation of $0.8 \%$. The Western Ghats in particular (where the study area is located), characterize many of the conservation problems posed by forest fragmentation. A recent estimate accounts for the loss and conversion of the original natural vegetation of the Western Ghats during 1920-1990 to be around 40\%, with an annual rate of deforestation of around $0.57 \%$ and a fourfold increase in the number of fragments (Menon and Bawa, 1997). This is a major concern as forests resources are foreseeable for the human health; ecological balance and economy hence, need continuous monitoring to evaluate the landscape cover.

The literature survey and field visits of the study area revealed that many conservational measures were taken to improve of habitats and forest after declaring it as National Park. Tree plantation, development of grass lands, evacuation of twenty eight villages, complete ban on commercial exploitation of the forest resource and fishing in the reservoir, restricted entry of local people inside the protected area were some of the measures taken by the forest department (Anonymous, 2005). Not only this, the government of India has augmented its status from sanctuary to National Park and now as tiger reserve (National Tiger Conservation Authority 2008). These developments encouraged the author to consider Chandoli National Park as a case study to evaluate the impact of conservation and management measures implemented inside the protected area.

The information about the landscape may be obtained by visiting sites on the ground or extracting it from remotely sensed data. The studies on landscape types carried out by conventional methods, like gridded mirror technique or ocular estimate of tree canopy cover for evaluating the forest crown density (Hussain et al., 2008) and random sampling for vegetation evaluation (Chako, 1965; Ilyas, 2001; Kushwaha et al., 2004), is a formidable task (Adeniyi, 1980). These techniques are time consuming and do not provide a holistic picture. 
Monitoring forests cover from the space, in contrast, can provide relevant information quickly, as well as repeatedly and at regular intervals of time. Since the early 1970s, satellite data have been commonly used for evaluating the landscapes. Many studies have demonstrated the effectiveness of using remotely sensed data as a powerful tool to study the land use patterns for critical environmental areas, vegetation dynamics and urban expansion (Howarth and Wickware, 1981; Sugumaran et.al., 2003; Podeh, et al., 2009). The concept of remote sensing data and its use in mapping and evaluating the forest has been taken momentum in India also. As early as 1985, Gautam and Chenniah prepared land-use and land-cover map of Tripura using Landsat imagery data. Kushwaha et al. (2000) used remote sensing data in mapping the forests of Kaziranga National Park (Assam) for evaluating the habitat changes that occurred in the park after flood, while Chauhan et al. (2003) analysed aerial photographs of 1976 and satellite data of IRS- 1C,- LISS- III of 1999 and evaluated the changes in density of sal forest. In 2005, Lele et al. (2005) used remote sensing data for analyzing forest cover dynamics in north-east India. Singh et al. (2006) monitored forest plantations and also assessed the effect of settlements on growing stock in Tahno range of Dehradun Forest Division. Okhandiara (2008) selected remotely sensed data of IRS-1D and IRS-P6, LISS-III to evaluate the forest landscape of Kannod Forest Subdivision of Dewas district, India. Recently, Chakraborty (2009) used moderate resolution imaging spectroradiometer (MODIS) to study the forest cover of Barak basin, north eastern part of India.

Therefore, considering remote sensing and geographic information system (GIS) as an important and potential tool in evaluating the landscape cover, this technique was used for the present study.

\section{STUDY AREA}

Chandoli National Park lies within $17^{0} 04^{\prime} 00^{\prime \prime} \mathrm{N}$ to $17^{0} 19^{\prime} 54^{\prime \prime} \mathrm{N}$ and $73^{\circ} 40^{\prime} 43^{\prime \prime}$ E to $73^{\circ} 53^{\prime}$ 09" E and encompasses an area of $319.97 \mathrm{~km}^{2}$ (Fig. 1). This National Park (NP) was primarily declared as protected area (PA) to conserve biological diversity of the region as well to protect catchments of Warna river on which a dam and reservoir is built.

Chandoli NP is mainly stretched along the crest of the north sahyadri range of bio-geographic province of Western Ghats mountains, India. This bio-geographic zone supports 27\% (400015000 species) of all the higher plant species recorded in India, out of that about 1800 are 
endemic to this region (Imam and Yahya, 2009). The topography is undulating, with steep escarpments. The elevation ranges from $589 \mathrm{msl}$ to $1044 \mathrm{msl}$. A distinct feature of the park is the presence of numerous barren rocky lateritic plateaus, locally called the sadda. Geological foundation of the area is Deccan trap, the soils are mostly lateritic on the plateau and reddish brown with mixed origin on the hill slopes. Before the declaration of this forest area as NP, some of the forestlands were owned by the villagers as their private property and locally known as Malkiland.

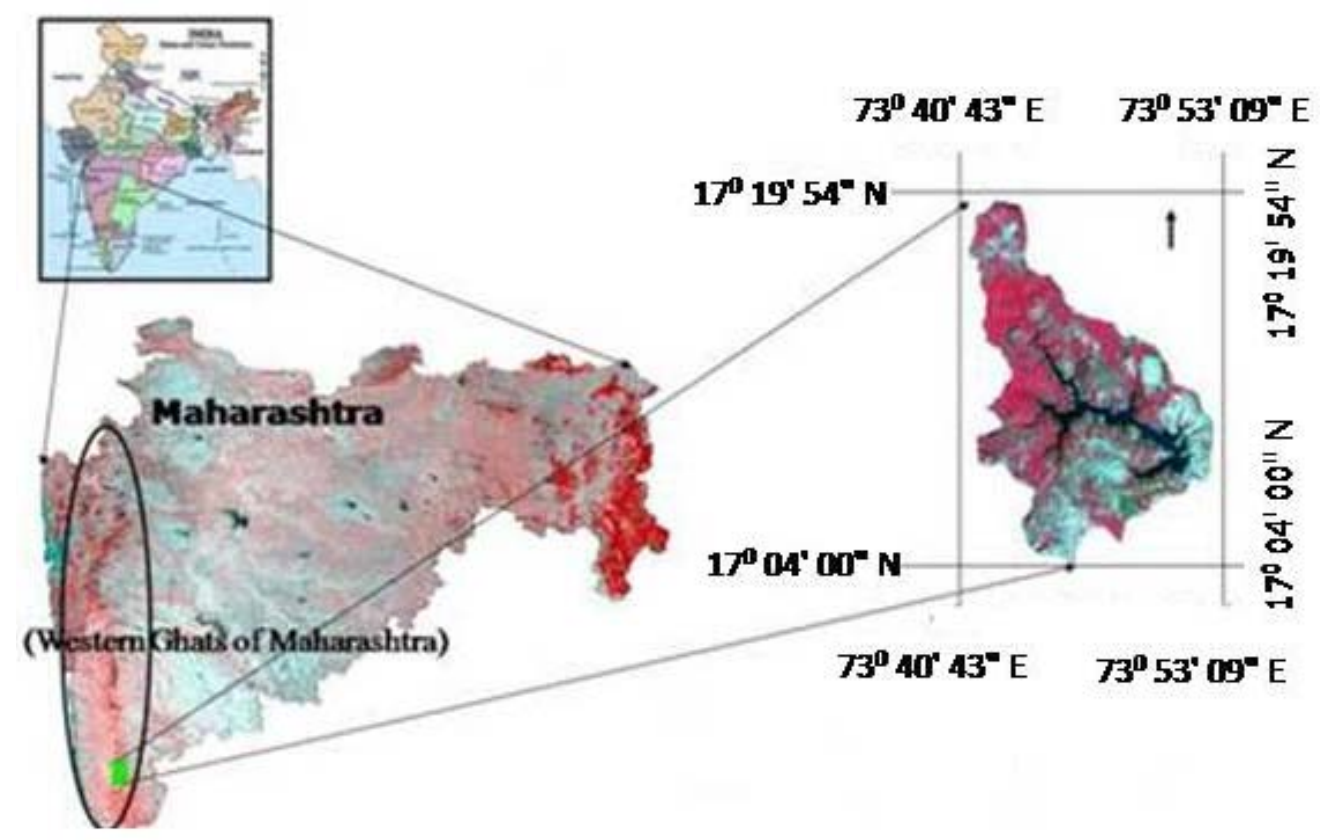

Figure 1. Study area Chandoli NP, India.

Chandoli National Park experiences a moderate climate with a maximum temperature of $38^{\circ} \mathrm{C}$ in summer and a minimum of $7^{0} \mathrm{C}$ in winter. Mean annual rainfall is $3,500 \mathrm{~mm}$. According to Champion and Seth (1968) the forest types include, western tropical hill forests, semi-evergreen forests and southern moist mixed deciduous forests. Dominant plant species include Anjani (Memecylon umbellatum), jamun (Sygyzium cumini) with associates Katak (Bridelia retusa), Kinjal (Terminalia paniculata), Amla (Phyllanthus emblica), Umbar (Ficus hispida), Harra (Terminalia chebula). Among grasses Bangala (Andorpogony), Dongari (Crysopogon fulvus), Saphet-kusli (Aristida funiculata) and bamboo species Bambusa bamboo (Kalak) are some of the common species. Chandoli NP has very few wild animals, probably due to anthropogenic 
pressure prior to being declared a protected area. However, bison (Bos gaurus), sambar (Cervus unicolor), muntjack (Muntiacus muntjak), leopard (Panthera pardus), tiger (Panthera tigris) are found in the protected area. In addition to Warna River 19 other perennial and 48 seasonal natural water sources are present inside the park (Anonymous, 2005).

\section{METHODOLOGY}

The study was carried out during April 2005 to December 2005 and completed in three phases. In the first phase satellite and collateral data were collected and processed, while during the second phase, field survey was conducted for ground truthing. The third phase included database creation and geospatial evaluation of landscape. ERDAS IMAGINE 8.7 (2004) and ArcView 3.2 (1999) computer softwares were used for data processing and GIS analysis.

\subsection{Data collection and data processing}

The primary data was obtained by field surveys and actual measurements using global positioning system (GPS) and camera. Secondary data was obtained from various sources like National Park maps, topographic maps, and satellite imageries.

\subsubsection{Satellite data}

Satellite data of Indian remote-sensing satellite-P6, linear imaging self-scanning satellite-III (IRS-P6, LISS-III) of dated $25^{\text {th }}$ February 2005, Path-95, Rows-060 and 061 was acquired from National Remote Sensing Agency (NRSA), Hyderabad, India.

The study area lies in two scenes of 095-60 and 095-61 (L1SS III). The satellite data was imported into ERDAS IMAGINE 8.7 software in an image format for geometric correction. In order to use these data in conjunction with other spatial data, it is needed to georeference the distorted data (raw data) to a coordinate system. The LISS data was co-registered with already rectified enhanced thematic mapper (ETM) satellite data of November 1999 considering it as a reference coordinate system. This method is known as image to image correction, which involves matching of the coordinate systems or column and row of two digital images with one image acting as a reference image and the other as the image to be rectified. Distortions were corrected using ground control points (GCP) and appropriate mathematical models.

In the present study about 20 well distributed prominent features like river, road junctions, drainage bends, drainage junctions, sharp ridge curves, isolated features and some big permanent structures available and identifiable on both the images (LISS and ETM) were considered as 
GCPs. During the process, GCPs were located on both images (distorted and already rectified) in terms of their coordinates; as column and rows on distorted image (LISS image) and as ground coordinates on already rectified ETM image in terms of universe transeverse mercator world geodetic system -84 (UTM WGS-84). These values were submitted to a least square regression analysis to determine coefficient for two coordinate transformation equations that is used to interrelate the geometrically correct image coordinates (here ETM image) and distorted image coordinates (here LISS image). All these mathematical notations were processed in ERDAS IMAGINE 8.7. The precision was measured through root mean square error (RMSE). The well distributed 20 GCPs improved the image rectification accuracy and brought the RMSE value as low as 0.2 , which is below 1 pixel and can be considered sufficiently accurate (Thakur et al., 2008). Then the two rectified scenes of 095-60 and 095-61 (L1SS III) were mosaiced using a model present in ERDAS IMAGINE 8.7 software. Image mosaicking is a process in which two or more than two images (already rectified to a standard map projection and datum) are combined into a single seamless composite image. From the mosaiced data, a subset of area of interest (AOI) was made for further analysis. Image was displayed as a False Color Composite (FCC) using three bands $(3,2,1)$ and colour prints were taken to the field for ground truthing.

\subsubsection{Collateral data}

The study area is covered by four different topographic sheets $(47 \mathrm{G} / 6,47 \mathrm{G} / 10,47 \mathrm{G} / 11$ and $47 \mathrm{G} / 14$; at 1:50,000 scale), therefore, all these maps were scanned and exported to ERDAS IMAGINE 8.7 in image format (.img) for geo-referencing to be used in conjunction with other spatial data. The values of latitudes/longitudes of quadrangle (grid intersections) was calculated manually and used as GCPs. For each topographic map, sixteen GCPs (12 from margins/corners and 04 from grid intersections) were picked up by placing "crosshair" over corners and quadrangle grid crossing of topographic map. These known coordinate data were entered into the model as; longitude of topographic map in X field and latitude of topographic map in the $\mathrm{Y}$ field in degree minutes seconds (DD MM SS) format, which is automatically converted to decimal form. Similarly, the other three topographic maps were georeferenced. The RMS error was maintained up to one-third of a pixel by placing the crosshair over accurate position of known coordinates (on topographic maps). The map was re-sampled using the nearest neighbourhood method and re-projected into universe transverse mercator world geodetic system-84 (UTMWGS 84) projection for further analysis (Lillesand and Kiefer, 1994). 
Then the four rectified topographic maps were mosaiced. This mosaiced map was overlayed/ swapped on rectified LISS image and its accuracy was checked by seeing overlapping of the features like roads, railway lines, crossing of canal etc. on each other. From the mosaiced data a study area of interest (AOI) was built around the park boundary to produce a rectilinear map for extracting information on various aspects of landscape cover, park boundary etc.

\subsubsection{Field survey}

Field surveys were carried out during $18^{\text {th }}$ to the 30th October 2005. Ground truthing was done by matching the pattern, texture association, shape and size of the features from the FCC for a particular topographic feature using GPS locations. Initially it was decided to use "line transects method" for collecting data for ground truthing. But later changed for an "opportunistic transect method" as forest areas were not always accessible due to high density of under growth and absence of accessible tracks and roads. The forest area on both sides of the reservoir was traversed on foot and GPS locations were noted.

\subsection{Post field work}

\subsubsection{Preparation of land-use land-cover map}

The land-use land-cover map of an area can give pattern of land utilization and also helps in evaluating the earth surface. Therefore, it is important to prepare land-use land-cover map. Satellite data (imageries) was used for creating False Colour Composite (FCC) that served as the basis to develop the land-use land-cover and forest density maps. The land-use land-cover map was prepared through digital analysis of satellite data using supervised maximum likelihood classification technique. Supervised classification is a procedure for identifying spectrally similar areas on an image by identifying 'training' sites of known targets and then extrapolating those spectral signatures to other areas of unknown targets. Supervised classification relies on the previous knowledge of the location and identity of land cover types that are in the image. This was achieved through field visits of the study area. Training areas (usually small and discrete compared to the full image) were used to "train" the classification algorithm to recognize land cover classes based on their spectral signatures, as found in the image. The maximum likelihood classifier (MLC) assumes that the training statistics for each class have a normal or 'Gaussian' distribution. The classifier then uses the training statistics to compute a probability value of whether it belongs to a particular land cover category class. This allows for within-class spectral variance. In this the image analyst uses a prior knowledge to weight the probability function. The 
MLC provides the highest classification accuracies (Lellesand and Kiefer, 1994), so that it was used in present case (Fig 1; Table 1).

Table 1. Area covered by different landscape, Chandoli National Park, India (2005).

\begin{tabular}{|l|l|}
\hline Land-use land-cover & Area (in $\mathbf{K m}^{\mathbf{2}}$ ) \\
\hline Evergreen Forest & 51.24 \\
\hline Scrub land & 87.60 \\
\hline Grass land & \\
\hline Malkiland & 71.70 \\
\hline River (water) & 35.52 \\
\hline Sada (Laterite rock) & 9.75 \\
\hline Total & 319.97 \\
\hline
\end{tabular}

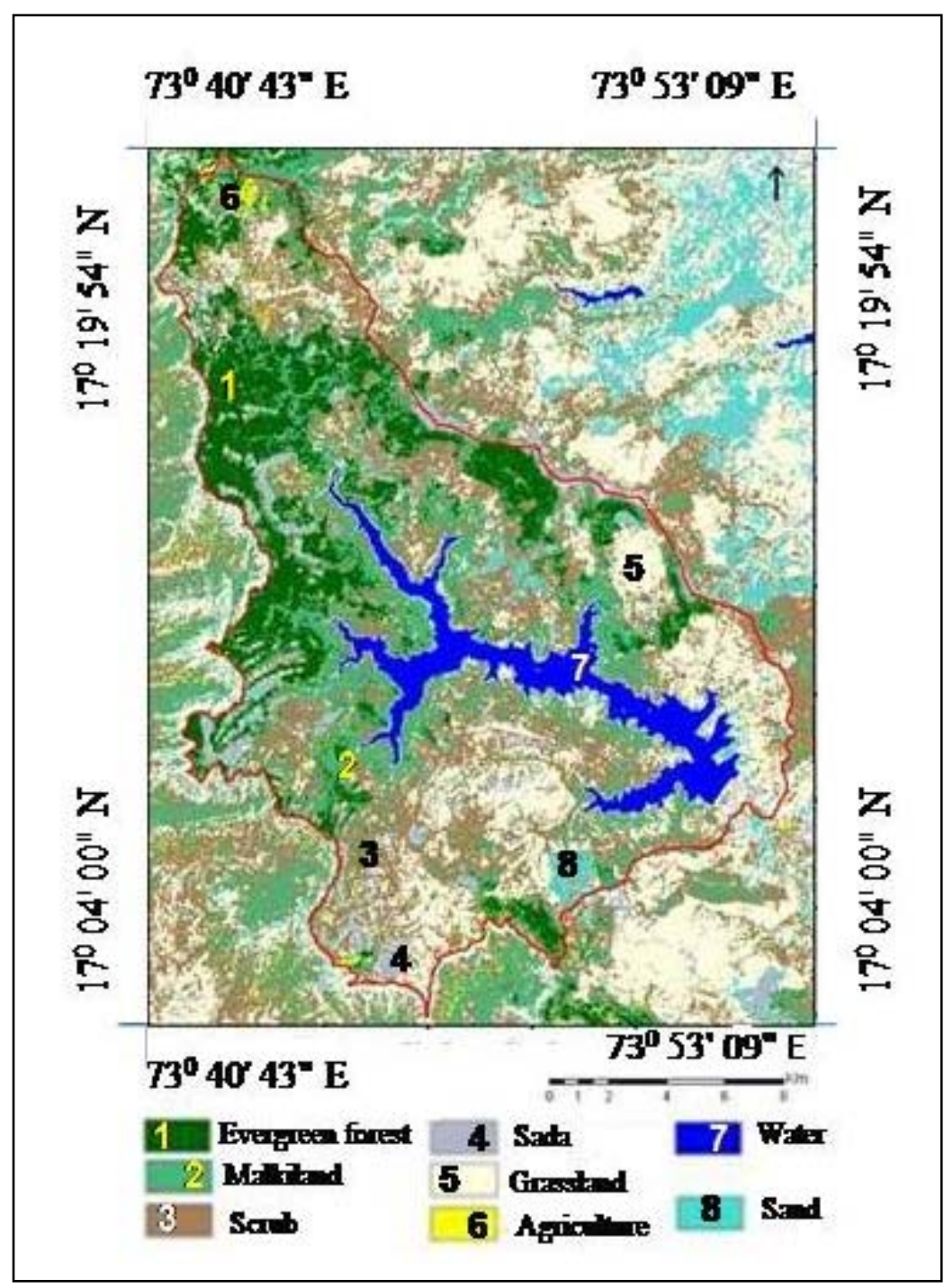

Figure 2. Land use, land cover map of Chandoli NP, India (2005). 
Table 2. Area of different forest crown density classes, Chandoli NP, India (2005).

\begin{tabular}{|l|l|}
\hline Forest Crown Density Class & Area (\%) \\
\hline $0-10$ & 26.08 \\
\hline $10-40$ & 34.31 \\
\hline $40-70$ & 22.97 \\
\hline More than 70 & 16.61 \\
\hline
\end{tabular}

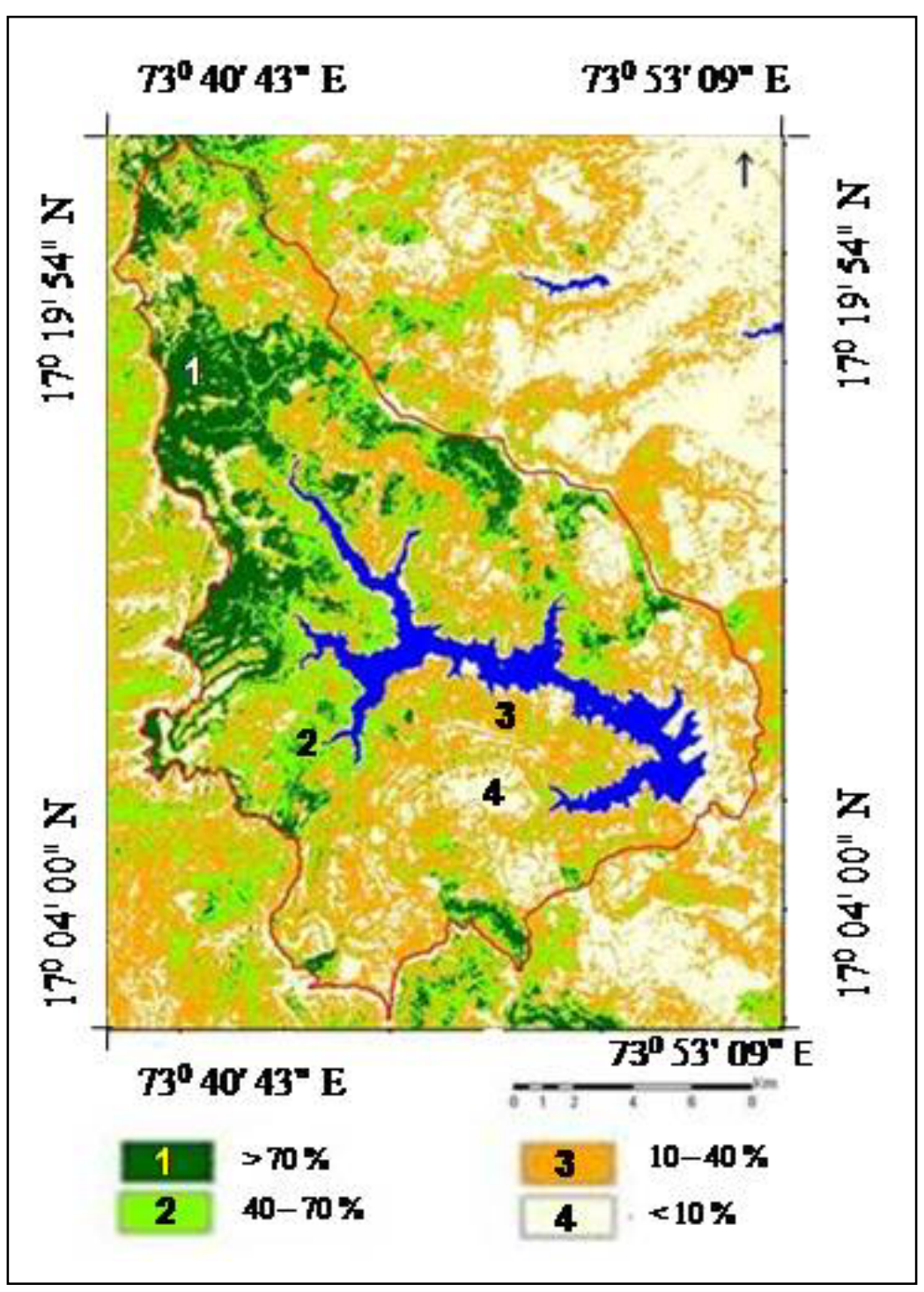

Figure 3. Forest crown density map of Chandoli NP, India (2005).

\subsubsection{Preparation of forest density map}

Forest density map provides information on the crown cover of the forest, which is an indicator of forest status. Normalized difference vegetation index NDVI was used to prepare a forest density map that was categorized into four canopy density classes: $<10 \%$ (non forest), $10-40 \%$ 
(open), 40-70\% (medium) and $>70 \%$ (dense). Image elements like tone, texture, shape, size, shadow, location and association were also evaluated to aid in the class delineations. NDVI is a method of measuring and mapping the density of green vegetation. For its measurement scientists use satellite sensors that observe the distinct wavelengths of visible and near-infrared sunlight which is absorbed and reflected by the plants, then the ratio of visible and near-infrared light reflected back up to the sensor is calculated. The ratio gives a number from minus one $(-1)$ to plus one $(+1)$. An NDVI value of zero means no green vegetation and close to $+1(0.8-0.9)$ indicates the highest possible density of green leaves.

The 'normalized difference vegetation index' is calculated by the formula: NDVI $=(\mathrm{IR}-\mathrm{R}) /(\mathrm{IR}+$ $\mathrm{R}$ ), where IR = infrared light and $\mathrm{R}=$ red light (Lellesand and Kiefer, 1994). The group of pixels having NDVI values from 0 to 0.3 were categories under canopy density class of $<10 \%, 0.3-0.5$ as canopy density class of $10-40 \%$, and $0.5-0.7$ were categorised as $40-70 \%$, whereas, the group of pixels having NDVI value 0.7-0.9 were kept under the canopy density class of $>70 \%$ (Fig 3; Table 2).

\section{RESULTS AND DISCUSSION}

The land-use land-cover map of Chandoli National Park depicts that out of $319.97 \mathrm{~km}^{2}$ only $51.24 \mathrm{~km}^{2}$ areas are left as dense evergreen forest (Fig $2 \&$ Table 1). This chunk of forest is confined to the northern part of the NP, where access is difficult and probably this may be the reason that the forest is not over-exploited. The possible reasons for depletion in dense forest are anthropogenic pressures faced by the park continuously for several decades. A detailed analysis of topographic maps (SOI, 1977) of the study area and other secondary information shows that Chandoli National Park was initially covered with about $172.14 \mathrm{~km}^{2}$ of evergreen dense forest. Originally, 32 villages with several hamlets were present inside the protected area and contained a human population of 7,900. Whereas, within $10 \mathrm{~km}$ radius of National Park, about 78 villages with a human population of 10,150 (1981 Census) were also present. It is reported that most of the villagers were either laborer or marginal farmers depending partially or fully on the forest resources to meet their requirements of fuel, timber, habitation and fodder for their livestock. The total number of livestock present in the protected area accounted for 2800 with another 75,000 found within a $10 \mathrm{~km}$ radius of the National Park (Anonymous, 2005). The dependency 
of such a large number of human population and livestock on the protected area has led to the depletion of forest resources.

The impact of anthropogenic pressures was also analyzed by evaluating the status of scrub land. The land-use land-cover map (2005), illustrate that $87.60 \mathrm{~km}^{2}$ of NP is covered with scrub land. The secondary data collected from topographic maps (SOI, 1977) suggests that area of scrubland has increased in due course of time. This increase might be in part attributed to the conversion of lost forest into scrubland caused by either the indiscriminate cutting of the trees that reduced the open forest into an early stage i.e. scrubland or by the development of evacuated area into scrubland due to protection from overgrazing.

The land-use land-cover map also depicts that an area of $64.19 \mathrm{~km}^{2}$ of grass lands are present in the south-east, south-west and extreme northern part of the National Park. However, the 1977 topographic map (SOI, 1977) shows no such areas as grassland. It is reported that development of grasslands occurred due to the planting of grasses over $6.9 \mathrm{~km}^{2}$ and because of natural growth in agricultural lands that were evacuated by villagers. During the field visit, it was observed that 28 villages (out of 32) that were evacuated had played a major role in the recovery of this cover type.

The Malkiland covers an area of $71.7 \mathrm{~km}^{2}$ and spread throughout the park, mostly along the river. However, on comparing with the topographic map of 1977 (SOI, 1977), it is identified that previously Malkiland encompassed an area of $97.66 \mathrm{~km}^{2}$. As discussed previously this forestlands were owned by the villagers in earlier times as their private property, therefore it was over-exploited. After declaration of the area as National Park this land has now reclaimed and parts have rejuvenated into "secondary forest". Inspite of protection and conservation, only $71.7 \mathrm{~km}^{2}$ of Malkiland has been restored as "secondary forest" and the rest has either been converted into scrublands or grasslands. In my opinion, this is probably due to loss of fertile top soil making it unsuitable for supporting large size trees, and because a portion of the Malkiland was also submerged by the reservoir after dam construction.

A distinct feature of the park is the presence of numerous barren rocky lateritic plateaus, locally known as sada. These are spread throughout the park and cover an area of $9.75 \mathrm{~km}^{2}$. Sadas are usually flat to slightly inclined and have a tremendous amount of loose scattered laterite. The sadas areas were one of the most preferable habitat for wild animals as during field visits author 
encountered with various indirect evidences (like scats, pug marks, kill, hoof mark, dropping and feeding evidences) of presence of herbivores and carnivores.

The land-use land-cover map (Fig. 3, Table 2) revealed that an area of $35.52 \mathrm{~km}^{2}$ is covered by water. An analysis of topographic map (1977) indicates that before the construction of the dam on Warna river, the area covered by water within the park was only $4 \mathrm{~km}^{2}$. After construction of a dam in 1985 on the river, a reservoir emerged, which submerged fairly large patches of good forests of the park and this may be another reason of losing of some of the dense forest. Not only this, reservoir has separated the National Park almost into two halves, creating barrier for wild animals movement from one parts to another. The evaluation of crown density of Chandoli National Park revealed that $16.61 \%$ of forested areas are covered by crown density of more than $70 \%$, which are spread in northern part of the park. This part of the park is possessing intricate terrain and due to the restricted access to the area, forest is not over exploited by the villagers, so that crown density is maintained (more than 70\%). The forest areas with crown density class of $40-70 \%$ are mainly distributed along the dense forests covering $22.97 \%$ of the Park. These forests are rejuvenating (secondary growth) and taking the shape after protection and conservation of the park. Contrary to this, a large chunk of forests (34.31\%) are covered by crown density of $10-40 \%$ and most of them are confined to southern part of the park. These areas were easily accessed by the villagers, so faced severe anthropogenic pressure in the past and probably due to this its crown density is poor. The rest of the National Park (26.08\%) is covered by crown density of $0-10 \%$, which is restricted to the extreme south of the park. The field visits revealed that areas covered with crown density of $0-10 \%$ is mostly grass lands and barren scattered stones or sada. Although these types of area is having very low crown density but they are important from wildlife point of view as various direct and indirect evidences of animals' presence were recorded in these habitat during the survey.

\section{CONCLUSION AND RECOMMENDATION}

The present study revealed that Remote Sensing and GIS are becoming important tools for ecological studies. Satellite imageries are potential of providing land-use land-cover and forest crown density maps, and these maps can be used for evaluating the forest status. The evaluation of forest revealed that Chandoli National Park has diversified habitats. The comparative analysis suggests that there is an improvement in forest status and Park is becoming more suitable for 
wild animals than prior to its designation as a Protected Area. This is also advocated by the habitat suitability analysis (Imam, 2005), which suggests that about $136.37 \mathrm{~km}^{2}$ of forest area (almost half of the National Park) of Chandoli NP has become suitable for tigers.

My study suggests that, in future by declaring specific areas as a National Park, and providing them additional protection, appears to be a strategy to enhance desirable landscape cover types for wildlife. Our present time tells us of a scenario whereby we are losing wild animals habitats continuously, thus declaring additional Protected Area may be a big step towards achieving floral as well as faunal conservation.

\section{ACKNOWLEDGEMENTS}

The author is thankful to Head, Forestry and Ecology Division, Indian Institute of Remote Sensing (IIRS), Dehradun, India for his guidance and GIS-laboratory facilities. Thanks are also due to Director and forest staffs of Chandoli National Park, Maharashtra, India for their logistic support during my field studies. I am also thankful to Dr. Alem, Dean College of Natural and Computational Science and my colleagues Dr. Tadesse, Mr. Dawit, Mr. Meheretu and Mr. Zewdneh from Department of Biology, Mekelle University, Mekelle, Ethiopia for their valuable suggestions and computer facilities. Finally, I am thankful to anonymous reviewers for their critical comments and suggestions, which helped me in improvement of manuscript.

\section{REFERENCES}

Anonymous. 2005. Management Plan of Chandoli National Park, Kolhapur Forest Division, Maharashtra, India. 190pp.

ArcView 3.2, 1999. Environmetal System Research Institute's GIS vers. 3.2. Environmental Systems Research Institute, Inc., Redlands, CA, USA.

Burgi, M., Hersperger, A.M \& Schneeberger, N. 2005. Driving forces of landscape change: current and new directions. Landscape Ecology, 19: 857-68.

Chako, V.J. 1965. A manual of sampling Techniques for forest surveys. Delhi, India: Managers Publication.

Chakraborty, K. 2009. Vegetation change detection in Barak Basin. Current Science, 96: 12361242. 
Champion, H.G \& Seth, S.K. 1968. A Revised Survey of the Forest Types of India. Dehradun, India: Forest Research Institute.

Chauhan, P. S., Porwal, M. C., Sharma, L \& Negi, J. D. 2003. Change detection in Sal forest in Dehradun forest division using remote sensing and geographical information system. Journal of the Indian Society of Remote Sensing, 31: 211-218.

ERDAS IMAGINE 8.7. 2004. Leica Geosystems GIS and Mapping. gis.leicageosystems. com.

FAO, 1990. Survey of tropical forest cover and study of change process, forest resource assessment, FAO forestry paper.

Gautam, N.C \& Chennaiah, G. C. 1985. Land-use and land-cover mapping and change detection in Tripura using satellite LANDSAT data. International J. of Remote Sensing, 6: 517-528.

Howarth, P.J \& Wickware, G. M. 1981. Procedures for change detection using Landsat digital data. Internotional Journal of Remote Sensing, 2: 277-291.

Hussain, M.S., Sultana, A., Khan, J.A \& Khan, A. 2008. Species composition and community structure of forest stands in Kumaon Himalaya, Uttarakhand, India. Tropical Ecology, 49: 167-181.

Ilyas, O. 2001. Status and conservation of ungulates in the Kumaon Himalayas with special reference to aspect of ecology of barking deer Muntiacus muntjak and goral Nemorhaedus goral., PhD Thesis, Aligarh Muslim University, Aligarh, India.

Imam, E. 2005. Habitat suitability analysis for tiger in Chandoli National Park, Kolhapur using Remote Sensing and GIS. Dissertation, Indian Institute of Remote Sensing, Dehradun, India.

Imam, E \& Yahya, H.S.A. 2009. Primates of India.Udaipur, India: Sadguru Publication.

Kushwaha, S.P.S., Khan, A., Habib, B., Quadri, A \& Singh, A. 2004. Evaluation of Sambar and muntjak habitats using geostatistical modelling. Current Science, 86: 1390-1400.

Kushwaha, S.P.S., Roy, P.S., Azeem, A., Boruah, P \& Lahan, P. 2000. Land area change and habitat suitability analysis in Kaziranga National Park, Assam. Tigerpape, 27: 9-17.

Lambin, E. F., Baulies, X., Bockstael, N., Fischer, G., Krug, T., Leemans, R., Moran, E. F., Rindfuss, R. R., Skole, D., Turner, B. L \& Vogel, C. 1999. Land use and land cover change LUCC.: implementation strategy, IGBP Report no.48/ IHDPReport no. 10, ICBP, Stockholm. Mensuration and Management, University of Helsinki, Helsinki, Finland, 31-42.

Lele, N. V., Joshi, P. K \& Agarwal, S. P. 2005. Remote Sensing for Forest Cover Dynamics in North-East India. Indian Journal of forestry, 28: 217-224. 
Lillesand, T. M \& Kiefer, R. W. 1994. Remote Sensing and Image Interpretation. New York: John Wiley and Sons.

Menon, S \& Bawa, K. S. 1997. Applications of Geographic Information Systems GIS., remotesensing, and a landscape ecology approach to biodiversity conservation in the Western Ghats. Current Science, 73: 134-145.

Millennium Ecosystem Assessment. 2005. Overview of the Millennium Ecosystem Assessment 2005.

National Tiger Conservation Authority. 2008. Ministry of Environment and Forest, Government of India, February 12.

Okhandiara, R. R., Rajub, P.L.N \& Bijkerc, W. 2008. Neighborhood correlation image analysis technique for change detection in forest landscape. The International Archives of the Photogrammetry, Beijing: Remote Sensing and Spatial Information Sciences. Vol. XXXVII. Part B8.

Podeh, S. S., J. Oladi, J., Pormajidian, M. R \& Zadeh, M. M. 2009. Forest change detection in the north of Iran using TM/ETM+Imagery. Asian Journal of Applied Science, 2: 464-474.

Singh, I. J., Mizaurahaman, M \& Kushwaha, S. P. S. 2006. Assessment of effect of settlements on growing stock in Tahno range of Dehradun Forest Division using Remote Sensing and GIS. Journal of Indian Society of Remote Sensing, 34: 209-217.

SOI. 1977. Topographic maps of study area;47G/6,47G/10,47G/11 and 47G/14at 1:50000 scale, Survey of India, Government of India.

Sugumaran, R., Pavuluri, M.K \& Zerr, D. 2003. The use of high-resolution imagery for identification of urban climax forest species using traditional and rule-based classification approach. Geoscience and Remote Sensing, 41: 1933 - 1939.

Tahir, M \& Hussain, T. 2008. Environmental Geography. New Delhi: Jawahar Publishers and Distributors.

Thakur, A. K., Sing, S \& Roy, P. S. 2008. Orthorectification of IRS-P6 LISS-IV data using Landsat ETM and SRTM datasets in the Himalayas of Chamoli District, Uttarakhand. Current Science, 95: 1459.

Vitousek, P. M., Mooney, H. A., Lubchenco, J \& Melillo, J. M. 1997. Human domination of Earth's ecosystems. Science, 277: 494-499. 